\title{
Neonatal renal and inferior vena cava thrombosis associated with fetal thrombotic vasculopathy: a case report
}

\author{
Lorenzo Giacchetti ${ }^{*}$, Martina De Gaudenzi ${ }^{2}$, Andrea Leoncini ${ }^{3}$, Elisabetta Ferrucci ${ }^{1}$, Valdo Pezzoli ${ }^{1}$ \\ and Manuela Albisetti ${ }^{4}$
}

\begin{abstract}
Background: Fetal thrombotic vasculopathy is a described placental diagnosis associated with adverse perinatal outcomes. It may also predispose children to somatic thromboembolic events. As far as we know, this is the first case of inferior vena cava thrombosis associated with fetal thrombotic vasculopathy in a completely asymptomatic newborn.

Case presentation: We report the case of an asymptomatic, full-term Turkish male neonate delivered at 39 weeks of gestation diagnosed as having thrombosis of the renal vein and inferior vena cava. Diagnosis was guided only by the presence of edematous umbilical cord with macroscopic signs of clotting and, subsequently, microscopic features of the placenta, suggesting fetal thrombotic vasculopathy.

Conclusions: Thrombosis of the renal and inferior vena cava in our healthy, asymptomatic full-term neonate is clearly associated with fetal thrombotic vasculopathy. The diagnosis of thrombosis in this neonate was incidental. This suggests that fetal thrombotic vasculopathy may cause unrecognized neonatal thrombosis. Untreated neonatal thrombosis may later compromise growth and function of the involved organs; therefore, maintaining a high index of suspicion based on thrombotic vasculopathy is paramount.
\end{abstract}

Keywords: Neonate, Venous thrombosis, Fetal thrombotic vasculopathy, Umbilical cord

\section{Background}

The vast majority of neonatal thromboembolic events (TEs) are related to catheterization and most of their discoveries are secondary to clinical manifestations [1]. Fetal thrombotic vasculopathy (FTV) is a recently described placental diagnosis associated with adverse perinatal outcomes. Neonates from mothers who have FTV are more likely to have intracranial hemorrhage, coagulopathy, neurological impairment, growth retardation, and evidence of systemic thrombosis/vasculopathy $[2,3]$.

We report the case of an otherwise healthy asymptomatic neonate who was discovered to have thrombosis of the inferior vena cava (IVC) on imaging. An ultrasound was performed on the baby due to edema and

\footnotetext{
* Correspondence: lorenzogiacchetti@gmail.com

${ }^{1}$ Department of Pediatrics, Regional Hospital of Lugano, Via Tesserete 46, 6900 Lugano, Switzerland

Full list of author information is available at the end of the article
}

macroscopic signs of thrombosis observed in the umbilical cord. The placenta histologically showed signs of FTV.

\section{Case presentation}

A full-term male Turkish neonate was delivered at 39 weeks of gestation by an urgent caesarian section due to fetal heart rate decelerations, after a failed attempt of vacuum-assisted vaginal delivery. The pregnancy of his 30 -year-old gravida 4 para 2 mother had been uneventful. She had previously experienced two spontaneous abortions of unclear etiology. Their family history was negative for coagulopathies.

The neonate was asymptomatic at birth, showing a good transition to extrauterine life. An initial physical examination revealed no pathologic findings; Apgar scores were 7, 9, and 9 at 1,5 , and 10 minutes of life, respectively, and arterial cord $\mathrm{pH}$ was 7.24. His body 
weight was 3420 grams, body length $52 \mathrm{~cm}$, and head circumference $34 \mathrm{~cm}$. A neurological examination revealed no abnormalities.

The obstetrician reported difficulties in clamping and cutting the umbilical cord, which appeared edematous and showed signs of clotting and hematoma (Fig. 1). On macroscopic examination, the placenta showed signs of FTV. On histologic examination, thrombosis of several fetal vessels of the chorionic plate and avascular terminal villi, including a macroscopic visible thrombosis of the umbilical artery in an edematous umbilical cord, were demonstrated (Figs. 2 and 3)

Despite his normal clinical appearance, an abdominal ultrasound was performed to rule out any conditions potentially related to placental FTV. The ultrasound revealed a hyperechoic oval structure $(8.5 \times 4 \mathrm{~mm})$ inside his IVC near the conjunction of his renal veins, suggestive of an intraluminal caval thrombus (Fig. 4). Of note, a cranial ultrasonography revealed no abnormalities.

He was admitted to our neonatal division for clinical monitoring and observation. In accordance with the pediatric hematologist, anticoagulation with low-molecularweight heparin (enoxaparin) at a dose of $1.5 \mathrm{mg} / \mathrm{kg}$ twice a day was started, targeting an anti-Xa between 0.5 and 1.0 $\mathrm{U} / \mathrm{ml}[4]$.

Two days later, a second ultrasonography confirmed the presence of a thrombus of $7.5 \times 4 \mathrm{~mm}$, extending into his IVC from his right renal vein. His ipsilateral kidney was slightly more hyperechoic with respect to the left, suggesting parenchymal edema (Fig. 5). Magnetic resonance imaging confirmed the diagnosis. His creatinine reached a maximum value of $127 \mu \mathrm{mol} / \mathrm{L}$ on the same day; this value is high for neonatal age [5] suggesting initial renal vein involvement. His blood pressure was always normal.

A third ultrasonography performed at day of life 7 showed a reduction in the size of the thrombus and normalization of his kidney structure. Accordingly, his creatinine decreased to normal values. He was discharged at day of life 8, in good clinical condition and with enoxaparin to be continued for 3 months. Another ultrasound

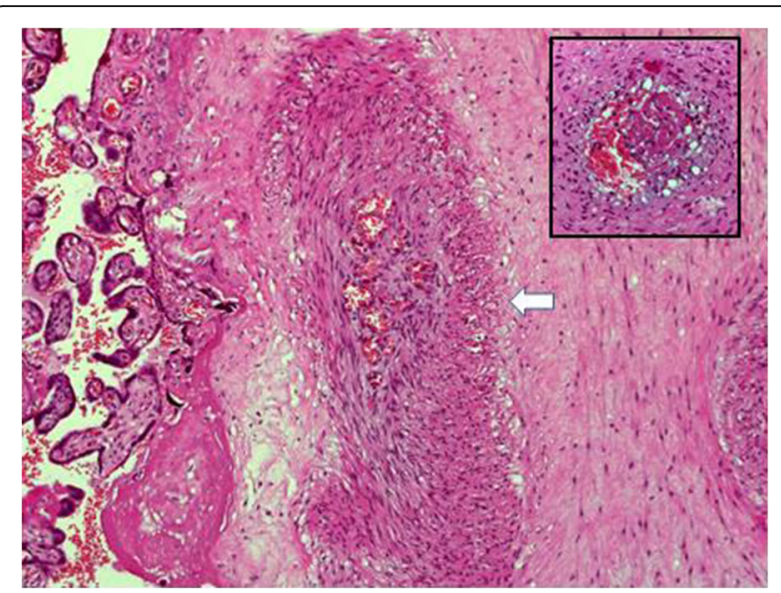

Fig. 2 Organized thrombus and recanalized stem villus (large photo arrow); thrombus not completely organized (top right)

examination at day of life 28 showed an almost complete resolution of the thrombus (Fig. 6).

Thrombophilia screening in his mother showed a prothrombin gene G20210A heterozygous mutation. Thrombophilia screening in the child was performed at 3 months of age with normal results. He was in excellent clinical condition at 1-year follow-up, and is thriving normally.

\section{Discussion}

TEs in infancy, both arterial and venous, are rare but linked with a high risk of morbidity and mortality, which is why several countries are collecting data on these patients in national registries. Neonates have a higher incidence of thrombosis as compared to older children. It has been suggested that neonates are particularly susceptible to such thrombotic complications, as they have decreased levels of anticoagulants and lower levels of fibrinolytic components. The physiologic decrease in activity at different levels of the hemostatic system usually leads to a balance of the prothrombotic and antithrombotic components in healthy neonates.

In the literature, the reported incidence of symptomatic venous TEs ranges from 0.07 to $0.14 / 10,000$ children
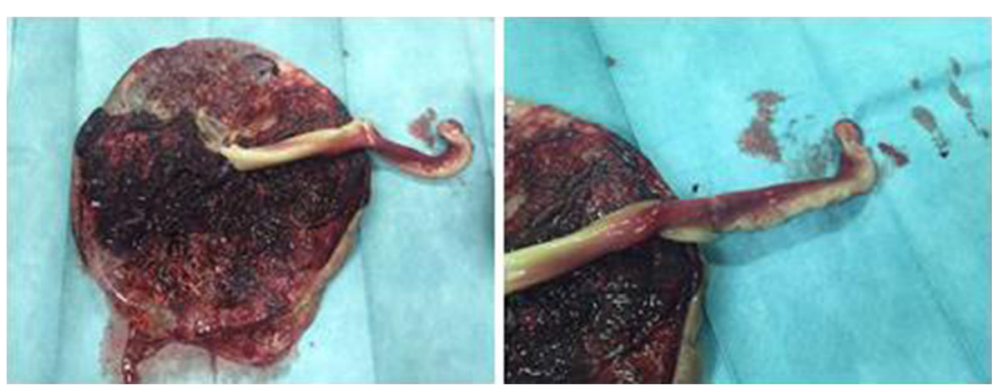

Fig. 1 Placenta and umbilical cord at birth 


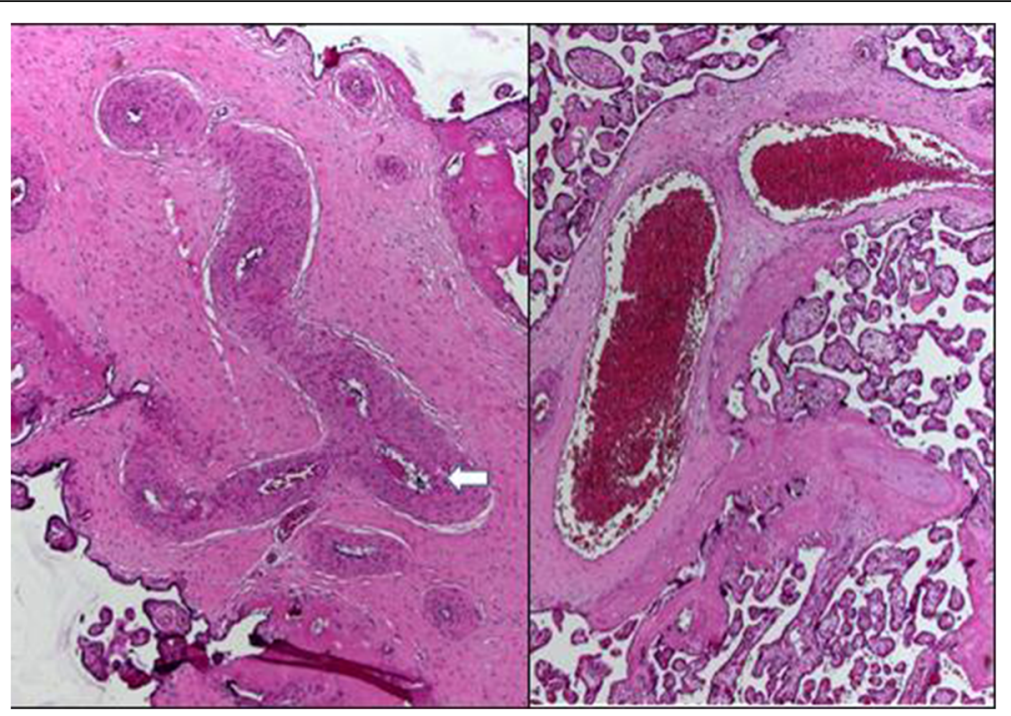

Fig. 3 Stem villous vessels with thrombus (arrow) and stenosis (pictured left). Stem villous vessels normally pervious, for comparison (pictured right)

and is 24/10,000 patients in neonatal intensive care units [6-8]. Several studies based on national and international registries have evaluated the role of risk factors for thrombosis both in children and neonates [6-8]. While the vast majority of venous TEs in neonates and children are associated with the presence of central venous lines, renal vein thrombosis represents the most common non-catheter-related cause of venous TEs occurring during the neonatal period [1]. The etiology of renal vein thrombosis is not precisely known. Reported associated risk factors include perinatal asphyxia, maternal diabetes, and infections [1]. To the best of our knowledge, renal vein thrombosis associated with FTV has not been reported so far.

FTV is a placental abnormality characterized by clusters of not adequately vascularized villi that is often related to upstream thrombosis in placental fetal vessels [9]. On microscopic examination, FTV is diagnosed by the presence of one or more thrombosed fetal vessels. In 2004, the Fetal Vascular Obstruction Nosology Committee formally defined FTV as the presence of 15 or more avascular villi or

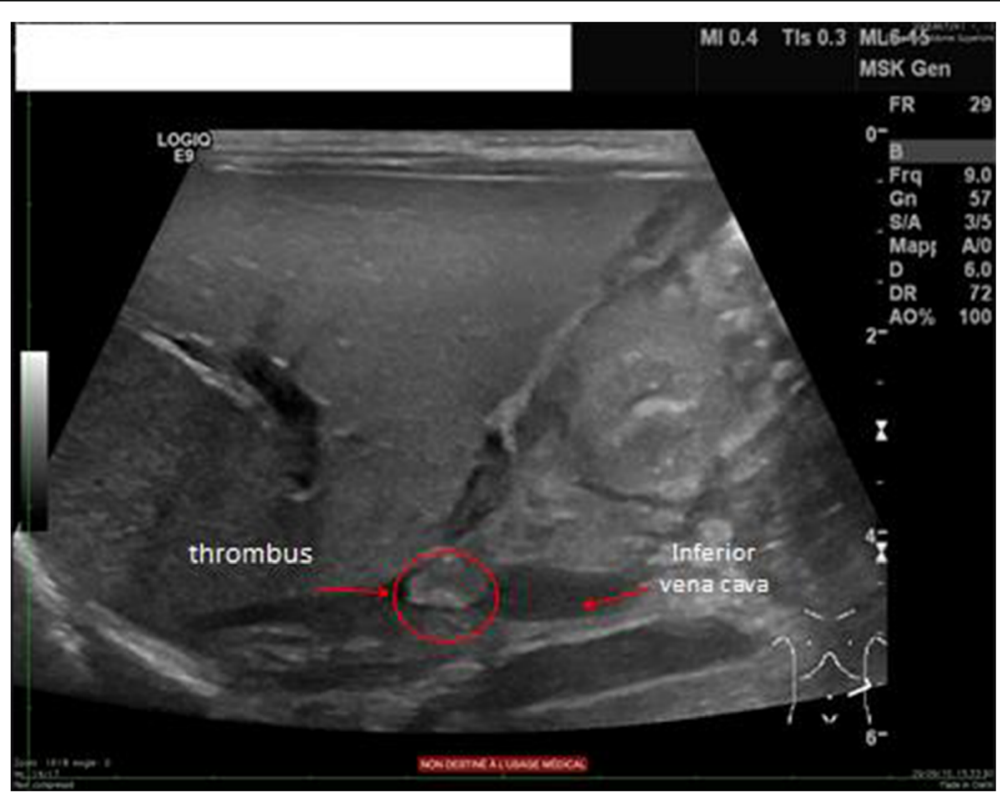

Fig. 4 Hyperechoic oval structure $(8.5 \times 4 \mathrm{~mm})$ at the level of the inferior vena cava near to the opening of the renal veins suggestive of an intraluminal caval thrombus 


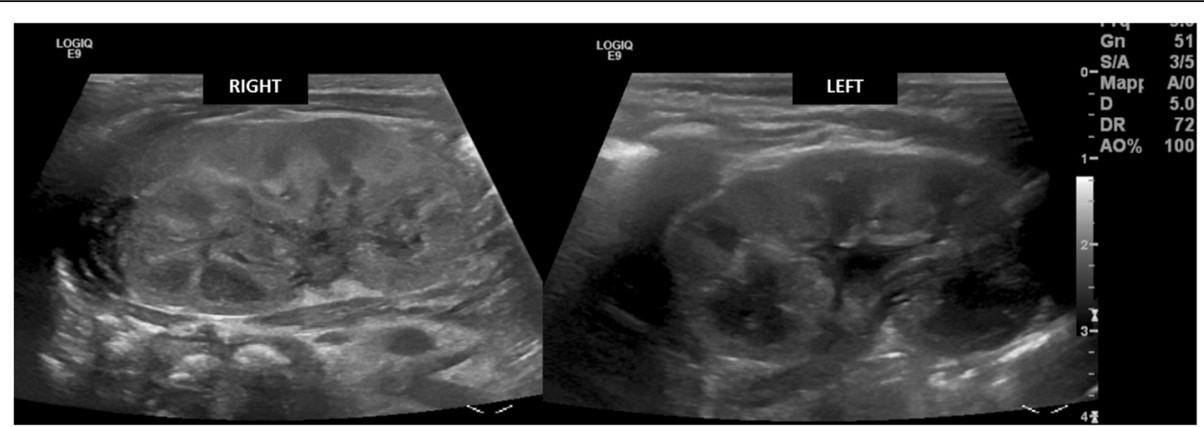

Fig. 5 Right kidney parenchyma appears more finely and diffusely hyperechoic than the left

villous stromal-vascular karyorrhexis in two or more foci per slide, with or without an identifiable fetal vessel lesion and in the absence of "villitis of unknown etiology with stem villitis and avascular villi" [10]. On the basis of this definition, the incidence of FTV in the several studies varies from 1 to $6.4 \%$ [11]. The etiology and clinical features of FTV are mostly unknown. Some conditions such as hypercoagulable state, endothelial damage, blood flow stasis, maternal diabetes, and thrombophilia have been associated with FTV [12]. Obstructive cord abnormalities such as excessively long or hypercoiled cord, entanglement, true knots, marginal/membranous insertion, decreased Wharton's jelly, cord diameter $<8 \mathrm{~mm}$ are closely associated with FTV and consequently to neonatal thrombosis $[9,13]$.

Despite there being no consensus on the causes of FTV, the adverse outcomes of this vasculopathy have been described, raising an evolving concern. Intrauterine growth retardation, fetal demise, intestinal atresia, and thromboembolism into the fetal circulation probably affecting liver, heart, and central nervous system are included [14].

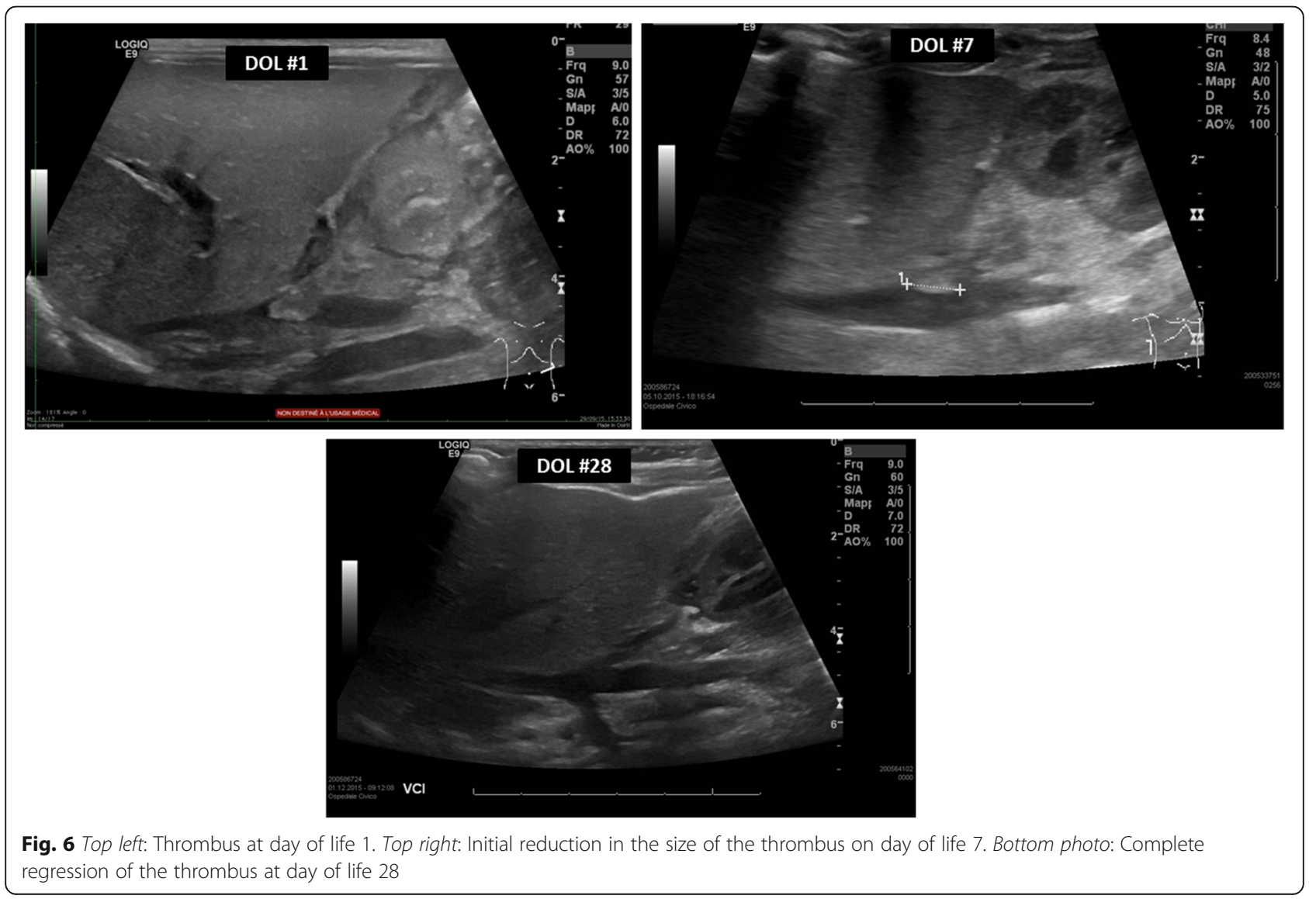




\section{Conclusions}

Our case report stresses two important considerations. First, thrombosis of the renal vein and IVC in our healthy asymptomatic term neonate is clearly associated with FTV. Thus, FTV should be included among the reported causes of renal vein thrombosis in neonates. Furthermore, the incidental nature of the diagnosis of thrombosis in this neonate suggests that unrecognized FTV possibly leads to unrecognized neonatal thrombosis, which in turn may compromise growth and function of the involved organs. Our case underlines the importance of macroscopic examination of the umbilical cord and placenta at delivery. Suspected FTV should lead to microscopic examination of the placenta and ultrasound examination of the neonates to exclude thrombosis of major vessels.

\section{Abbreviations}

FTV: Fetal thrombotic vasculopathy; IVC: Inferior vena cava; TEs: Thromboembolic events

\section{Funding}

None.

\section{Availability of data and materials}

The authors agree to make the images and materials described in our manuscript freely available.

\section{Authors' contributions}

$L G, M D$, and MA carried out the literature research, manuscript preparation, and were the main moderators of the manuscript. MA, VP, AL, and EF revised the manuscript. $A L$ supported us with the imaging studies. All authors read and approved the final manuscript.

\section{Ethics approval and consent to participate}

The ethics committee of the Ticino Canton in Switzerland does not require any ethical approval or consent for participation in the studies relating to clinical case reports.

\section{Consent for publication}

Written informed consent was obtained from the patient's parents for publication of this case report and any accompanying images. A copy of the written consent is available for review by the Editor-in-Chief of this journal.

\section{Competing interests}

The authors declare that they have no competing interests.

\section{Publisher's Note}

Springer Nature remains neutral with regard to jurisdictional claims in published maps and institutional affiliations.

\section{Author details}

'Department of Pediatrics, Regional Hospital of Lugano, Via Tesserete 46, 6900 Lugano, Switzerland. 'Department of Pediatrics, University of Pavia, Pavia, Italy. ${ }^{3}$ Department of Radiology, Regional Hospital of Lugano, Lugano, Switzerland. ${ }^{4}$ Division of Hematology, University Children's Hospital, Zurich, Switzerland.

Received: 19 September 2016 Accepted: 20 July 2017

Published online: 28 August 2017

\section{References}

1. Kuhle S, Massicotte P, Chan A, Mitchell L. A case series of 72 neonates with renal vein thrombosis. Data from the 1-800-NO-CLOTS Registry. Thromb Haemost. 2004;92(4):729-33.
2. Wintermark P, Boyd T, Parast MM, Van Marter LJ, Warfield SK, Robertson RL, Ringer SA. Fetal placental thrombosis and neonatal implications. Am J Perinatol. 2010;27(3):251-6.

3. Lepais L, Gaillot-Durand L, Boutitie F, Lebreton F, Buffin R, Huissoud C, Massardier J, Guibaud L, Devouassoux-Shisheboran M, Allias F. Fetal thrombotic vasculopathy is associated with thromboembolic events and adverse perinatal outcome but not with neurologic complications: a retrospective cohort study of 54 cases with a 3-year follow-up of children. Placenta. 2014;35(8):611-7.

4. Monagle P, Chan AK, Goldenberg NA, Ichord RN, Journeycake JM, NowakGöttl U, Vesely SK, Physicians ACoC. Antithrombotic therapy in neonates and children: Antithrombotic Therapy and Prevention of Thrombosis, 9th ed: American College of Chest Physicians Evidence-Based Clinical Practice Guidelines. Chest. 2012;141(2 Suppl):e737S-801.

5. Boer DP, de Rijke YB, Hop WC, Cransberg K, Dorresteijn EM. Reference values for serum creatinine in children younger than 1 year of age. Pediatr Nephrol. 2010;25(10):2107-13.

6. Schmidt B, Andrew M. Neonatal thrombosis: report of a prospective Canadian and international registry. Pediatrics. 1995;96(5 Pt 1):939-43.

7. Nowak-Göttl U, von Kries R, Göbel U. Neonatal symptomatic thromboembolism in Germany: two year survey. Arch Dis Child Fetal Neonatal Ed. 1997;76(3):F163-7.

8. van Ommen $\mathrm{CH}$, Heijboer H, Büller HR, Hirasing RA, Heijmans HS, Peters M. Venous thromboembolism in childhood: a prospective two-year registry in The Netherlands. J Pediatr. 2001;139(5):676-81.

9. Saleemuddin A, Tantbirojn P, Sirois K, Crum CP, Boyd TK, Tworoger S, Parast MM. Obstetric and perinatal complications in placentas with fetal thrombotic vasculopathy. Pediatr Dev Pathol. 2010;13(6):459-64.

10. Redline RW, Ariel I, Baergen RN, Desa DJ, Kraus FT, Roberts DJ, Sander CM. Fetal vascular obstructive lesions: nosology and reproducibility of placental reaction patterns. Pediatr Dev Pathol. 2004;7(5):443-52.

11. Gersell DJ. Selected vascular lesions of the placenta. Clin Lab Med. 1995:15(3):611-29.

12. Williams MD, Chalmers EA, Gibson BE. Haemostasis and Thrombosis Task Force BiCfSiH: The investigation and management of neonatal haemostasis and thrombosis. Br J Haematol. 2002;119(2):295-309.

13. Redline RW. Clinical and pathological umbilical cord abnormalities in fetal thrombotic vasculopathy. Hum Pathol. 2004;35(12):1494-8.

14. Kraus FT, Acheen VI. Fetal thrombotic vasculopathy in the placenta: cerebral thrombi and infarcts, coagulopathies, and cerebral palsy. Hum Pathol. 1999;30(7):759-69.
Submit your next manuscript to BioMed Central and we will help you at every step:

- We accept pre-submission inquiries

- Our selector tool helps you to find the most relevant journal

- We provide round the clock customer support

- Convenient online submission

- Thorough peer review

- Inclusion in PubMed and all major indexing services

- Maximum visibility for your research

Submit your manuscript at www.biomedcentral.com/submit
) Biomed Central 